\title{
TENDENCIES IN THE DESIGN OF THE GROUNDING DEVICES FOR THE ELECTRICAL INSTALLATIONS OF THE BELARUSIAN ENERGY SYSTEM
}

\author{
Mikhail Drako ${ }^{1, *}$, Siarhei Baraishuk ${ }^{2}$. \\ 1Scientific-Research Project Republican Unitary Enterprise, 5, 1st Tverdy lane, Minsk, 220038, Republic of Belarus \\ ${ }^{2}$ Belarusian State Agrarian Technical University, 99, Nesavisimosti av., Minsk, 220023, Republic of Belarus
}

\begin{abstract}
The paper considers the reasons to improve the design system for the grounding devices. It proposes a special-purpose composite mixture to reduce the soil electrical resistivity values. A number of field experiments were carried out to measure the resistance values of the grounding devices of the experimental circuits, after their near-electrode soil space had been treated with a special mixture to optimize the electrical resistivity of the grounding connection.
\end{abstract}

\section{Introduction}

The grounding should meet the requirements to ensure the safety of people and animals, protect high-current and low-current electrical installations, and also provide operational modes of service and lightning protection [1].

The connection of the grounded constructional parts of the electrical installation with the ground is provided by means of the bare conductors contacting the ground and meant to conduct current into it, which is called grounding connection. The grounding connection and the grounding conductors combined are called a grounding device (GD).

The structure of a GD of an electrical installation shall, at minimal construction expenses, in any season, provide standardized values of GD electricity parameters during a standard life period of an electrical installation [2].

A considerable number of GDs of the energy system are produced as the grounding rods altogether connected in various ways. A distinctive characteristic of such grounding connections is that the size of their separate parts' lateral dimensions, as a rule, are significantly less than those of their lengths'. It allows one, when calculating basic electricity parameters (such as dissipation resistance, distribution of a potential and field density), to neglect uneven variations of the current density distribution along the lateral cross-section generatrix of the elements [3]. Horizontal electrodes made of steel stripes or round steel are used either as the combiners for the vertical electrodes, or as the autonomous grounding connections. The cross-section of the GD vertical electrodes is chosen due to their mechanical strength and corrosion resistance [4]. Reference [5] gives thorough description of problematic questions of the grounding connections' corrosion in the electrical installations of the Belarusian energy system. The experience of surveying metal structures of electricity transmission lines and substations, provided in reference [6], affirms that in the climatic conditions of Belarus the corrosion mainly affects metal elements either at a ground level, or at $0.2 \mathrm{~m}$ above and beyond the ground level. With the aim to preserve the grounding conductors' longer life and operability it is necessary to perform anti-corrosion protection [7].

The soils of high and excessive corrosion aggressiveness are rarely met in the Republic of Belarus. The electrical resistivity values of the soils of identical types in all districts of the republic differ insignificantly and may be estimated in average values. In different types of soils, excluding sand, an anticipated value of the electrical resistivity is not greater than 600 OHMM [5].

Considering the depth of soil freezing in Belarus (approximately $1.8 \mathrm{~m}$ ), active conductive capacity of a vertical 5 meter electrode to conduct current into the ground equals only $3.2 \mathrm{~m}$. The result analysis of a geoelectrical cross-section of the soil ground level at the power objects of Belarusian energy system has proved that the soils, having higher level of electrical conductivity and electrical resistivity value, up to 100 OHMM, in most cases underlay no deeper than $5 \mathrm{~m}$. That is why a great number of vertical electrodes and significant additional land area for an artificial grounding connection are needed in some cases in order to reach standard values of GD electricity parameters.

As a rule, the irrational overuse of steel in the traditional grounding systems result in extra capital investment. However, electric safety and electric lighting and internal overvoltage protection of the electrical equipment are not enforced.

The problem connected with the vertical electrodes, mentioned above, can be solved by means of a deep vertical grounding connection (made of compound or

* Corresponding author: m.drako@besp.by 
one-piece tubes). According to reference [4] such grounding connections are advisable to be used in electricity system construction under two main factors:

- the grounding connections can reach lower underlying soils with lower resistivity values, which allows them to lower their own resistivity;

- a seasonal coefficient of the grounding connections being $10 \mathrm{~m}$ and longer approximately equals 1 .

However, there are no standard designs of using deep grounding connections in the Belarusian energy system. The design of GD having deep grounding connections can raise the price of such project, considering it is custom-designed.

In the course of design, installation and operation of GDs in the soils having high electrical resistivity it is recommended to use certain technical decisions to lower the electrical resistivity values of the grounding connection. One of them is to use soil treatment with the grounding connection material friendly substances and mixtures, which lower the soil electrical resistivity around the electrode $[8,9]$. To provide the contact of the compound deep grounding connections with the ground along its whole length, reference [2] recommends, while dipping the electrode, to grout in clay or other type of electricity conductive binder, which is not subject to erosion during the life and operation process.

It should be mentioned that 13 years has already passed since the time when SPA Belenergo methodological instructive regulations, covering the problem solving of design and construction of the grounding connections at the electrical stations and substations with rated voltage $35-750 \mathrm{kV}$, started to be implemented. Thus there is a strong necessity nowadays to reconsider and complete technical regulatory documents $[2,5]$, and also consider the possibility of a controlled implementation of the modern technological design decisions related to the GDs of the electrical installations of the Belarusian energy system. As, for example, a chemico-physical mineral electricity conductive composite mixture was developed in Belarus. It normalizes the grounding connection providing a lower level of the electrical resistivity by means of dispersed introduction of modifying additive compounds. Some of them, given below, to the author's point of view, are promising trends in the design of GDs of the electrical installations of the Belarusian energy system.

\section{Special Conductive Compounds}

One of the useful methods to lower the soil electrical resistivity in the soil of the GD construction site, as well as the soil electrical resistivity of the artificial grounding connection itself, can be a soil treatment with specialpurpose compound mixture with a low electrical resistivity value, non-corrosive, stabilizing moisture [9, 10] in the near-electrode soil space. Thus the method provides a freezing temperature decrease fixing the unfixed water in the soil as well as the soil electrical resistivity decrease producing compound electrolytic solutions.
When infused, the electricity conductive mixtures of carbon-containing powders are highly effective to decrease high rated values of the soil electrical resistivity (around 400-600 OHMM), and have little effect at rated values of the soil electrical resistivity less than 100 OHMM, in the latter case it may only have a minor effect combined with the hydrostabilyzing substances, such as, for example, hydrolyzed polyacrylonitrilie. Based on standard documentation acting in the Republic of Belarus and on the Russian and foreign experience the authors conducted a set of experiments to find out how the above mentioned substances influence the electrical resistivity values of a GD compared to the reference values.

In the course of the experiments with the sandy-loam soil the experimental GD circuits were mounted. Those circuits looked as a vertical compound electrode, made of galvanized steel with a diameter of $16 \mathrm{~mm}$, the length of $3 \mathrm{~m}$ and of a horizontal fragment of a combining stripe sized $4 \times 50 \mathrm{~mm}$ of the same length, no additions used. The near-electrode soil space of the experimental circuits had been treated with special-purpose composite mixture or with one of the mixture's components to optimize the electrical resistivity of the grounding connection. Systematic measurements of GD's electrical resistivity had been held for more than three years by means of a four-conductor measuring method with the help of IS-10 measuring device at different temperatures, different air humidity and soil moisture values. Besides that, a set of soil electrical resistivity value measurements by means of the vertical electric sounding was conducted on the location site of the experimental and the reference circuits.

The research that analyzed how the mixture or its components influenced the DG's electrical resistivity values, had been conducted before [9].

The experimental electrical resistivity research results of the reference circuit (red curve), and of the circuit treated with the special-purpose composite mixture (green curve) are given in figure 1. Furthermore, we had analyzed the measuring dynamics of the electrical resistivity of the circuit treated with a single component: hydrolyzed polyacrylonitrilie [11] (black curve), which is a non-toxic, non-polluting substance used in agriculture. It should be mentioned that hydrolyzed polyacrylonitrilie is a basic moisturestabilizing component of the special-purpose compound mixture.

Due to the acquired measuring results we can conclude that the GD, which near-electrode soil space had been treated with a special-purpose compound mixture to decrease the value of GD's dissipation resistance, had a minimal electrical resistivity value. The mixture not only allowed reducing the variation of GD's dissipation resistance, it also allowed reducing GD's electrical resistivity values compared to those of the reference circuit's.

Combined use of the mixture lowers a soil freezing temperature at $4{ }^{\circ} \mathrm{C}$, thus making it possible to use higher values of the average annual lowest temperatures when specifying the climatic zone of the location site of the designed electrical equipment. 
The research [9] shows that there are two factors influencing the decrease of electrical resistivity values: the change of a seasonal coefficient and the decrease of the soil electrical resistivity in the near-electrode soil space, they allow correcting the resistance calculation of the grounding connection when using the mixtures during the GD installation process.

In those cases, when the special-purpose composite mixtures are used to optimize electrical resistivity of the grounding connection, a certain amount of initial soil from the near-electrode space is submitted to the mixture, that has a significantly lover electrical resistivity value in the operation mode.

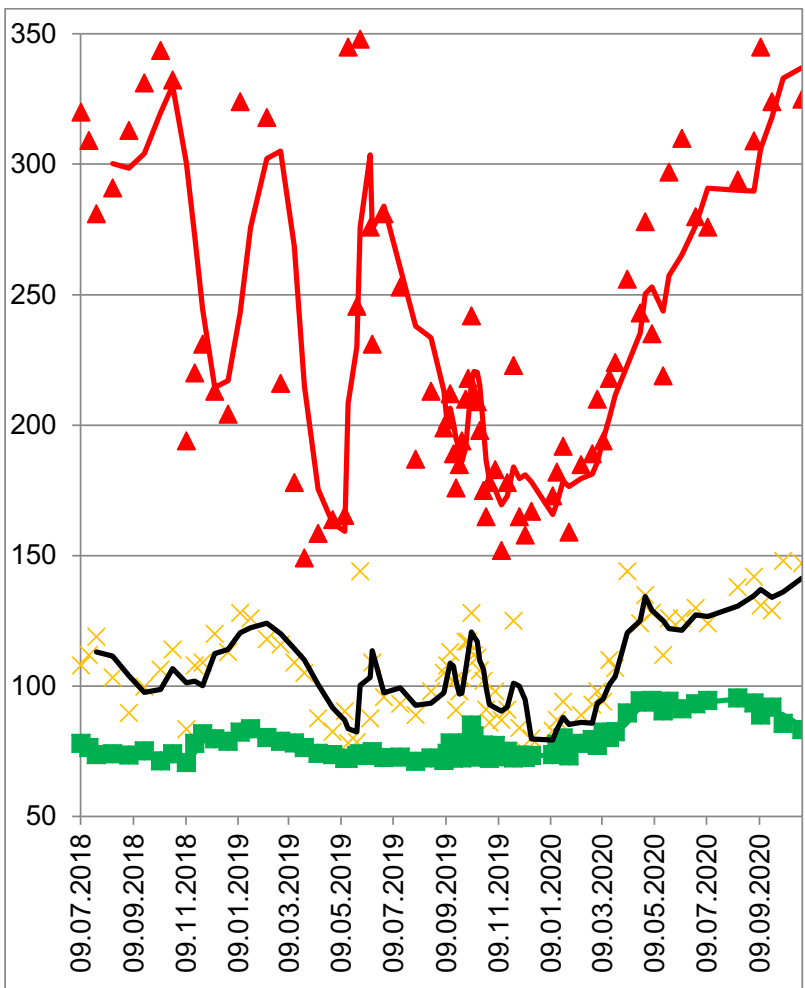

Fig. 1. The graph of the electrical resistivity of a reference GD (red curve), an experimental circuit treated with hydrolyzed polyacrylonitrilie (blue curve), and a circuit treated with a special-purpose compound mixture (green curve)

It is obvious that such submission is then the most effective one, when the difference between the electrical resistivity values of the soil and of the mixture is the greatest, and when the amount of the soil submitted from the near-electrode space of the GD is the greatest. Therewith the contact area of the mixture and the initial soli is a basic parameter that defines the change in resistance. In the case, when the mixture is used along the whole electrode length, this basic parameter is a contact perimeter. Thus, the effectiveness of soil submission drops exponentially down and for a significantly big perimeter (more than $1 \mathrm{~m}$ ) it becomes inappropriate. Experiments prove that the submissive mixtures are mostly effective when they create contact perimeters ranging from $0.4 \mathrm{~m}$ to $1.0 \mathrm{~m}$, whereby in order to calculate GD layout it is necessary to use equivalent soil electrical resistivity value instead of resistance measured value of the initial soil.

Equivalent soil electrical resistivity, given that a certain amount of soil was submitted with the mixture, is calculated by an analytic expression based on the experimental data for single-layered soil (1) and for double-layered soil (2):

$$
\begin{gathered}
\rho_{e q}=\Psi \cdot\left(\rho_{\text {soil }} e^{-1,3 / \mathrm{P}}+20 / e^{4 / \mathrm{P}}\right) \\
\rho_{\text {eq }}=\Psi\left(\frac{\rho_{\text {1soil }} \cdot \rho_{2 \text { soil }} \cdot l}{\left(\rho_{1 \text { soil }}(l-H+t)+\rho_{2 \text { soil }}(H-t)\right)} e^{-1,3 / \mathrm{P}}+20 / e^{4 / \mathrm{P}}\right)
\end{gathered}
$$

Where:

$\rho_{\text {eq }}$ - unknown equivalent soli electrical resistivity, OHMM;

$\rho_{\text {soil }}$ - measured soil electrical resistivity, OHMM; $\psi-$ a seasonal coefficient;

$H$ - the ground layer depth of the soil, m;

$l_{t r}$ - the depth of the trench, m;

$l$ - the length of a vertical grounding connection, $\mathrm{m}$; $P$ - a cross-section perimeter of the submitting mixture, $\mathrm{m}$.

In such cases, when a round cross-sectioned vertical compound grounding connection, which near-electrode soil space had been treated with the mixture, were buried into the soil, the equation to calculate the electrical resistivity of the grounding connection shall be written as:

$$
R_{v e r t}=\frac{\rho_{e q}}{2 \pi l}\left(\ln \frac{2 l}{d_{e q}}+\frac{1}{2} \ln \frac{4 t+l}{4 t-l}\right)
$$

Where:

$d_{e q}$ - an equivalent diameter of a grounding connection, $\mathrm{m}$, defined in accordance with (4).

$t$ - half-length of a vertical rod from the ground surface, $\mathrm{m}$.

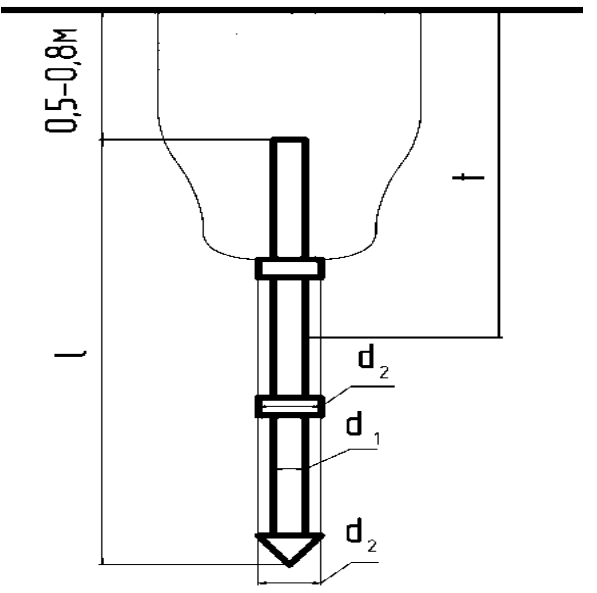

Fig. 2. Layout of a vertical compound grounding connection in the soil

Given is the amendment of change correction of the soil electrical resistivity in the near-electrode soil space 
(the amount of soil appears after the joint coupling has passed through the soil), while submitting the soil with the mixture having a low electrical resistivity value.

$d_{e q}=d_{g e}\left(1+\frac{\left(d_{\text {clutch }}-d_{g e}\right)}{d_{g e}} \cdot \frac{\rho_{e q}}{\rho_{\text {soil }}}\right)$

Where:

$d_{e q}$ - a diameter of a compound grounding connection;

$d_{g e}$ - a diameter of the grounding connection, $\mathrm{m}$;

$d_{\text {clutch }}$ - a diameter of a coupling joint, $\mathrm{m}$;

$\rho_{\text {soil }}$ - the measured soil electrical resistivity, OHMM.

While researching the mixture's influence on the seasonal coefficient it was settled that when the horizontal stripe had been covered with the mixture, the seasonal coefficient decreased at $20 \%$ in comparison with the reference circuit. In the cases when the installed vertical electrodes as well as their near-electrode soil space had been treated with the special-purpose composite mixture, the seasonal coefficient decreased at $25 \%$ in comparison with the reference values of an untreated circuit.

\section{Grounding Plates}

In the Republic of Belarus the principal design decisions for the lightning protection, the grounding and the bonding systems shall be described in the sub-section Electricity Supply, Power Equipment and Light of the section Engineering Equipment, Networks and Systems of an Architectural Design of the Civil Construction [12].

Bonding represents a particular case of an equipotential bonding protection, which it is not provided in the soil but on the surface, on which the personnel can move around.

Firstly, the GD shall comply with bonding demand, in order to ensure the electromagnetic compatibility at different conductive grounded parts of an electrical installation under all operational modes, including the emergency [13], when equal potential is provided, or its values do not overrate the limits acceptable for a given type of equipment, or an appliance of a given electrical installation. Reference [14] provides a detailed problem solving analysis of a hazardous potential in a lowvoltage network using the example of $110 / 35 / 6 / 0.4 \mathrm{kV}$ and $110 / 6 / 0.4 \mathrm{kV}$ cable overhead distribution power lines.

Current technical regulations $[2,4,8]$ in the design of GDs for the electrical installations of the Belarusian energy system pay insufficient attention to the application of the grounding plates, lattice plates in particular (figure 3), for the purpose of bonding.

The grounding plates are special type grounding connections developed mostly for the soils in which the vertical grounding connections either do not provide a desirable effect of reducing the electrical resistivity value when buried into the soil, or they are difficult to mount on the rocky soil. As calculated in accordance with the electricity contact, a grounding plate sized
$750 \times 500 \times 4 \mathrm{~mm}$ corresponds with a round steel vertical grounding connection sized $\varnothing 16 \mathrm{~mm}$ (in diameter) and is $15 \mathrm{~m}$ in length, however it is significantly easier mounted and reduces the ground works.

The grounding plates are prospective when they are mounted in the soil which ground surface soil electrical resistivity value is less than that of the subsoil's (as for example, significantly moist upper ground layer in the spring or in the autumn).
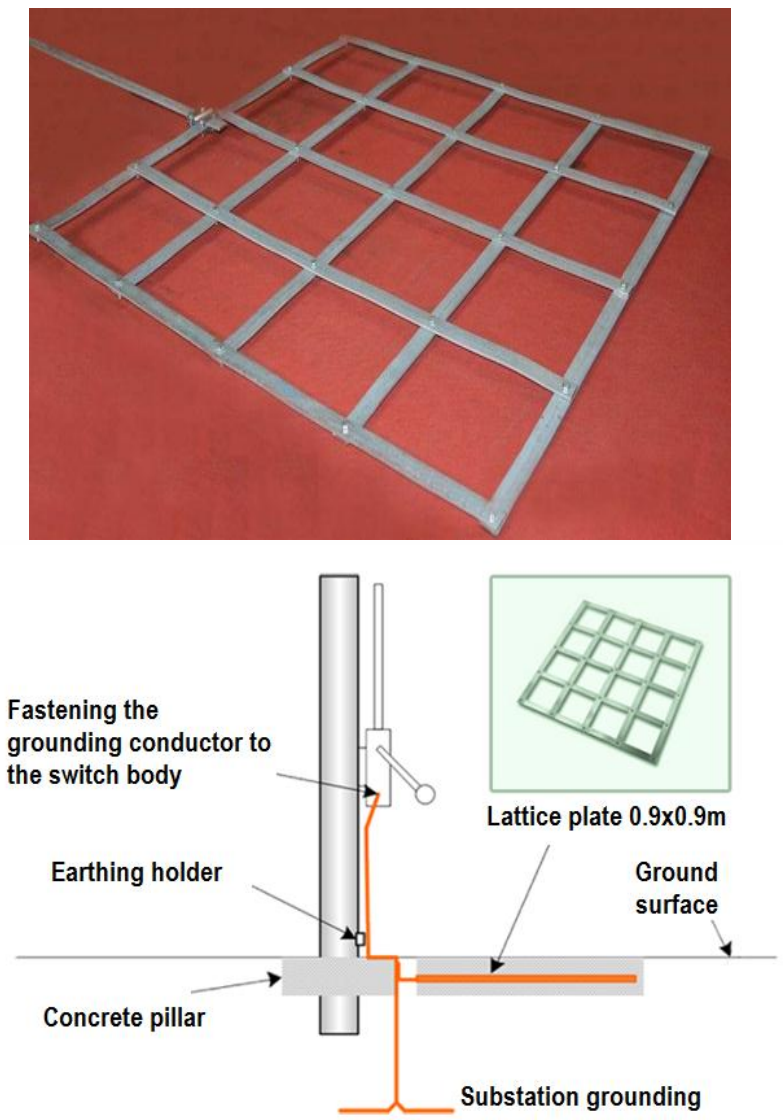

Fig. 3. Appearance (a) and advisable application (b) of the lattice plates

When developing the document [15] based on the analysis and the data processing of the soil electrical resistivity values acquired as the results of long term yearly physical measurements at the constructed electricity transmission lines and electrical substations, we have compiled a table of the electrical resistivity values for different types of the soils in the Republic of Belarus, which is possible to use when there are no proper measurement values.

The lattice grounding plates (figure 3, a), used together with the special-purpose composite mixture to normalize the grounding connection, provide the same electrical resistivity values of the DG, significantly reducing metal consumption at the same time, as do the solid metal grounding plates.

One of the most significant trends to use the lattice grounding plates is that their equipotential bonding ability when mounted at work-places of the electrical 
installations provides the electrical safety of the personnel.

\section{Conclusion}

1. Special-purpose composite mixtures based on hydrolyzed polyacrylonitrilie are most effective together with the grounding connections buried into the soil not deeper than the soil freezing depth, that is located within the soil layers exposed to the greatest seasonal variations, and it will increase provided the increase of the contact area of such grounding connections with the soil treated with the hydrolyzed polyacrylonitrilie.

2. Additional decrease of the seasonal coefficient for the vertical compound grounding connections is presumably provided by the mixture's influence at their compound parts mounted near the ground level of soil.

3. Special-purpose composite mixtures, which contain low-dispersed conductive substances, besides the hydrolyzing substances, provide a three-time reduction of GD's electrical resistivity value in comparison with the reference GD's values, they even the seasonal variations of GD's electrical resistivity, and they minimize capital investment on GDs mounting by reducing the number of electrodes and their location area [9].

4. Grounding plates used together with the specialpurpose composite mixture to normalize the grounding connection significantly reduce the ground works at the locations where the vertical electrodes are less effective. 5. Technical regulations $[2,4,8]$ are necessary to be reconsidered and actualized.

\section{References}

1. Titkov V.V. Overvoltage and lightning protection: textbook. SPb .: Publishing house of Polytechnical University, 2011, 222 p.
2. STP 09110.47.103-07. Minsk: SPA Belenergo, 2007, 75 p.

3. Ivliev E.A. Electricity, 1992, No. 7, pp. 41-44.

4. STP 09110.47.203-07. Minsk: SPA Belenergo, 2007. 48 p.

5. Draco M.A. Energy strategy, 2019, No. 6 (69), pp. 44-48.

6. Osipenko O. V., Drako M. A., Moiseenko O. A. Energy and Management, 2015, No. 1 (82), pp. 5-9.

7. Kolik V.R., Draco M.A., Moiseenko O.A. Energy Strategy, 2014, No. 2, pp. 23-25.

8. Acceptance test standards: TKP 339-2011 (02230). Minsk: Ministry of Energy of the Republic of Belarus, 2011, 593 p.

9. Baraishuk S.M., Pavlovich I.A. Agropanorama, 2020, No. 1 (137), pp. 20-23.

10. Shi L., Yang N., Zhang H., Chen L., Tao L., Wei Y., Liu H., Luo Y. novel poly (glutamic acid) /silksericinhydrogel for wound dressing: Synthesis, characterization and biological evaluation Materials Science and Engineering: C, 2009, Vol. 48 (1), pp. 533-540.

11. Shirinov Sh.D., Jalilov A.T. Universum: Chemistry and biology: electron. scientific. zhurn., 2018, No. 3 (45).

12. TKP 45-1.02-295-2014. Minsk: Minstroyarkhitektury, 2014, 45 p.

13. Borisov R.K., Zharkov Yu.V., Gorshkov A.V. Electro, No. 1, 2000, pp. 30-33.

14. Kuzmin I.A., Magdeev N.N., Evdokunin G.A., Brilinsky A.S., Grunina O.I. Electricity. Transmission and distribution. M.: Kabel, 2017, No. 5, pp. 84-91.

15. STP 09110.20.189-12. Appendix B (recommended). Typical album of grounding devices for overhead lines. Minsk: SPA Belenergo, 2012, 56 p. 